\title{
Perception of Causes and Consequences of Early Marriage: The Case of Gewane District, Afar Region, Ethiopia
}

\author{
Zebenay Shitaye (Msc) \\ College of Agriculture and Natural resource, department of rural development and agricultural extension, Debre \\ Markos University, p. o box 269, Debre Markos, Ethiopia \\ College of Agriculture, School of development, environment and gender studies Hawassa University, \\ P.O. Box 05, Hawassa, Ethiopia
}

\begin{abstract}
A study was conducted o investigate the perception of causes and consequences of early marriage at Gewane district, Afar regional state, Ethiopia. Cross sectional research design was applied for this specific study. Household survey, Key Informant Interviews and Focus Group Discussion was used to gather data. The data were analyzed using SPSS software version 20 by using binary logistic model and descriptive statistics. The study participant thought socio-cultural and economic motives as the major reasons for the practices of early marriage in the study area. Specifically, logistic regression analysis revealed respondents' family size, household monthly income and husbands having more than one wife as the significant factors determining early marriage. The study also indicates that unwanted pregnancy (32\%), abortion $(29.1 \%)$ and death $(21.2 \%)$ were the major health related consequences and termination of education (28.1\%), martial instability (25.6\%) and domestic violence $(17.7 \%)$ were the major socio- cultural consequences of early marriage in the study area. The study concludes that problems associated with early marriage are pertinent issue of women in the study area, as the practice that is supported by social norms and customs goes against their right. To overcome such a problem, awareness creation of the effect of early marriage should be promoted by family counselors, religious leaders, policy makers' social workers and other helping professionals to fight against such harmful traditional practices.
\end{abstract}

Keywords: Early marriage, Consequences, Socio-economic motives, Socio cultural reason, Discrimination, Perception, Traditional practices.

DOI: $10.7176 / \mathrm{DCS} / 9-10-03$

Publication date:October $31^{\text {st }} 2019$

\section{Introduction \\ Background}

Marriage is a social institution that unites people in a special form of mutual dependence for the purpose of founding and maintaining a family. As a social practice entered into a public act, religious or traditional ceremony, it reflects the purposes, character, and customs of the society in which it is found. Many societies have norms that limit the age of young girls to enter into marriage, but in some cases the age limit does not take into consideration their physiological readiness for childbearing. Marriage often takes place at age much earlier than the legally ratified minimum age. Early marriage is the marriage of children and adolescents below the age of 18. (Pathfinder International/Ethiopia, 2006)

Child marriage is a public health issue as well as a human rights violation. Girls married early are more likely to experience violence, abuse and forced sexual relations. Child marriages jeopardize girls' rights, such as the right to education, because new brides are usually forced to drop out of school to bear children and to provide household labor (Ingrid, 2009). In addition, married girls have few social connections, restricted mobility, limited control over resources and little or no power in their new households and are thus especially vulnerable to domestic violence (UNICEF, 2001a).

According to the International Planned Parenthood Federation-IPPF (2008) about 14 million girls under the age of 18 marry each year in the world. One in every 5 girls in the developing world is married by the age of 18 and one in nine girls marries before they reach the age of 15. In countries like Niger, Chad, Mali, Bangladesh, Guinea and the Central African Republic (CAR) the rate of early marriages is 60 percent and over. Child brides are particularly prevalent in South Asia (46 per cent) and in sub-Saharan Africa (38 per cent) (Locoh, 2008). Countries with the highest rates of early marriages in Europe include Georgia (17 per cent), Turkey (14 per cent) and Ukraine (10 per cent). At least 10 per cent of adolescents marry before the age of 18 in Britain and France (UNICEF, 2005).

The practice of early marriage is most common in sub-Saharan Africa and South Asia. In specific parts of West Africa, East Africa and South Asia, marriage before puberty is not unusual. In North Africa, the Middle East, and other parts of Asia marriage shortly after puberty is common among those living traditional lifestyles. Marriages of female adolescents between sixteen and eighteen years of age are also common in parts of Latin America and Eastern Europe (Pathfinder International/Ethiopia, 2006).

Early Marriage has reproduced adverse effects on the socioeconomic band health status of the persons 
involved. Girls who marry at early ages would lose the opportunity of formal education, have little or no opportunity for wage employment and hence mostly in the informal type of job or fully engages in housework and childcare. It may also lead into social power imbalances, such as unequal income generating opportunity, sexual violence, little money for attaining their daily needs and gender inequality in and out of their homes (Mutgan, 2014).

In 2010 alone, more than 67 million women who were found in the age brackets of 20 and 24 had been exposed for early marriage in developing countries except China (UNFPA, 2012). This is very worst in Africa in general and in Ethiopia in particular. In Ethiopia, from every 10 women who were getting into marriage in 2011, about 3 had married before maturity age (ibid). It is more prevalent especially in the rural communities of Christian dominated and agrarian society of the Central highlands and Northern part of Ethiopia. This part of the country accounts the $54.6 \%$ of the national incidence. In addition, the South and South- Western part of the country have the prevalence of $50-80 \%$ so far as child marriage is concerned (Mahdere, 2006).

The results of 2011 Ethiopian DHS show that, in 2011 the median age at first marriage was 16.5 among women aged 25-49 in all of Ethiopia, while median age for men between 25 and 59 years old was 23.1 ("CSAEthiopia \& ICF International", 2012; pp. 59). They have also found that women in rural areas have lower median age at marriage than women in urban areas (16.3 years 15 in rural, 18.1 years in urban), and women and men with no education have the lowest median age at first marriage compared to women and men with primary or higher level of education. Both women and men in Amhara region have the lowest median age at marriage, 14.7 and 20.9 respectively; while in Dire Dawa (18.9) and SNNPR (17.9) women have the highest age at marriage compared to other regions. Moreover, in Oromia region the median age at first marriage among women between 25 and 49 and among men between 25 and 59 years old, was 16.9 and 23.5 respectively.

\section{Statement of the Problem}

A number of national and international organizations and researchers have been conducted studies on the issues of harmful traditional practices, early marriage and its impacts from different dimensions (UNICEF, 2013; Rachel, 2013).

Giving little emphasis to other socio-economic factors, the National Committee on Traditional Practices in Ethiopia [NCTPE], 2003, UNICEF, 2011, UNICEF, 2007, Pass finder International/Ethiopia, 2010; WHO, 2014; $\mathrm{MoH}$, 2014) reported that due to the tradition of early marriage, Ethiopia become one of those countries with highest prevalence of obstetric fistula in the world. In terms of occurrence the further documented that although early marriage is widely practiced in many parts of Ethiopia; the rate in Amhara region (82\%) and Tigray region (79\%) are much higher than the national average (64\%) in Benishangul Gumz, (64\%) in Gambella (46\%) in Afar regions (NCTPE (2003). But none of these studies documented the extent of socio economic consequences of early marriage in Gewane wereda.

Therefore, the gap identified from most literatures is that causes and consequences of early marriage is not well studied in different ethnic cultures of the country. For this reason, this study will examine community members' perception of on the causes and consequences of early marriage in relation to its socio-economic grievances in Gewane woreda.

\section{Objectives of the Study}

General objective

General objective of this study is to assess perception on the causes and consequences of early marriage in the study area.

\section{The specific objectives}

$>$ To investigate the causes contributing for early marriage.

$>$ To assess the consequences of early marriage.

\section{Research Questions}

To analyze people's perception about early marriage.

\section{Scope of the Study}

$>$ What are the causes of early marriage?

$>$ What are the consequences of early marriage?

What is people's perception about early marriage?

The study focused on the perception of causes and consequences of early marriage in the pastoral communities, specifically deals with a limited number of households and focuses on the causes and effects of early marriage and the perception of the local comminutes towards early marriage. The study was limiting itself to only two (2) kebeles out of the nine (9) kebeles of Gewane Wereda. Meteka and Amasaburie kebeles were selected due to its accessibility and differences in socio- cultural composition of the pastoral/agro-pastoral community.

Significance of the Study

The Study is vital because it provides information that would fill required knowledge gap so as to design more effective and efficient strategies to stop early marriage. It provides also an opportunity to understand the local knowledge, skill and experiences which would help to further improve the existing impact of early marriage 
practices on women, specifically child mirage. Furthermore, it would enable development practitioners, development actors and policy makers implement effective strategies to reduce/stop the practice of early mirage. Limitations of the Study

The study covers only two (2) of the nine (9) kebeles of the study area. Moreover, the study deals with a limited number of married women and focused on the perceptions of causes and consequences of early marriage. The limitation of this study was limited by time, budget and other resource. Even if the study was restricted in terms of its coverage its outputs can be used as a spring board for more detailed and site specific studies.

\section{RESEARCH METHODOLOGY}

Study area:-This study was conducted in Gewane district located about $350 \mathrm{~km}$ east of the capital city, Addis Ababa. Found between $9^{\circ} 30^{\prime}$ and $10^{\circ} 20^{\prime} \mathrm{N}$ and $40^{\circ} 30^{\prime}$ and $40^{\circ} 50^{\prime} \mathrm{E}$, and between Upper and Lower Awash River Basins. The altitude of the study area ranges from 500 to $820 \mathrm{~m}$ a.s.1.

Research Design:-In order to examine the research questions and the practical reality in the study area, the researcher has used the cross sectional research design; because it examines varieties of a social phenomenon at a single point in time.

Sampling Method and Sampling Size:-Purposive sampling was used to select the study wereda and Kebeles. Two Kebeles: Meteka and Amasaburie were selected for the study. From the two Kebeles, a total of 203 respondents were selected using systematic random sampling techniques. Yamane (1967) provides a simplified formula to calculate sample sizes. The sample size was determined as follow.

$$
\begin{aligned}
& n=\frac{N}{1+N(e)^{2}} \\
& n=\frac{37349}{1+37349(0.07)^{2}} \\
& n=\frac{37349}{1+37349(0.0049)} \\
& n \approx 203
\end{aligned}
$$

Data Type and Sources:-The study relied on two main sources of data namely, secondary and primary data as well as mixing qualitative and quantitative data type. Primary data was gathered directly from respondents. Sampled married women, key informants and focus group discussants were primary data sources for this study. Secondary data collection was conducted by collecting information from a diverse source of documents and electronically stored information. The qualitative method involves subjective assessment of attitudes, opinions and behavior whereas the quantitative method is concerned with the generation of data in numeral form.

\section{Method of Data Collection procedures}

The following Instruments were used to collect data:

$>$ Structured Interviews: - is one of the most appropriate methods for the research problem speculation since interviews provide access to the meanings people attribute to their experiences and social worlds. Therefore, it has been used for this particular study to capture the necessary primary data.

$>$ Focus Group Discussion:- is another most relevant data gathering instrument that has been administered to gather the reality of the problem at hand. Two FGD was conducted in each selected kebeles with five to seven members and also Male and female participants were discussed separately.

$>$ Key Informant Interview:-One of the methods used for collecting information was key informant interview. As explained by Creswell (2009), interviews are important to gather information that may not be secured through other techniques, because they give an opportunity to listen respondents in person. Therefore, interview was conducted totally ten KIIS out of this, four are community leaders, one head of women and children's office of the district, two health officers, one development agent and two education officer, to support the data to be gathered through structured interviews. Interviews were held with key informants in their offices as they were available at the working hours. The questions were forwarded for the respondents focused on knowledge, attitude, practice, causes and consequences of early marriage practice in the study area.

Variables used in the study

\# The Response Variable

The response variable of this study is "married of women". For study purpose the response variable "married women" is coded 0 if a woman is married before 18 years and the coding for Married after 18 years is 1.

\section{\# The Explanatory Variables}

The predictor variables considered in this analysis include Age, marital status, education level, household 
livelihood, family size, household income, gender discrimination within family, dory paid of a woman.

RESULTS AND DISCUSSIONS

Demographic Backgrounds of the Respondents

Table 4. Socio-economic Background characteristics of the respondents

\begin{tabular}{|c|c|c|}
\hline Variables & Frequency & Percent \\
\hline Age & $n=203$ & 100 \\
\hline $18-30$ & 55 & 27.1 \\
\hline $31-40$ & 95 & 46.8 \\
\hline $41=50$ & 38 & 18.7 \\
\hline$>50$ & 15 & 7.4 \\
\hline educational level & $\mathrm{n}=203$ & 100 \\
\hline No formal education & 84 & 39.9 \\
\hline Read and write & 47 & 23.2 \\
\hline Quran & 12 & 5.9 \\
\hline $1-8$ th grade & 28 & 13.8 \\
\hline 9th-12th grade & 22 & 10.8 \\
\hline diploma and above & 13 & 6.4 \\
\hline religious status & $n=203$ & 100 \\
\hline Muslim & 191 & 94.1 \\
\hline Others & 12 & 5.9 \\
\hline Ethnicity & $n=203$ & 100 \\
\hline Afar & 188 & 92.6 \\
\hline Others & 15 & 7.4 \\
\hline family size & $n=203$ & 100 \\
\hline $2-5$ & 29 & 14.3 \\
\hline $6-8$ & 140 & 69.0 \\
\hline $9-12$ & 34 & 16.7 \\
\hline Hh income per month/birr & $n=203$ & 100 \\
\hline $451-650$ & 94 & 46.3 \\
\hline $651-800$ & 92 & 45.3 \\
\hline$>800$ & 17 & 8.4 \\
\hline Marriage of respondents & $n=203$ & 100 \\
\hline before 18 years & 146 & 71.9 \\
\hline after 18 years & 57 & 28.1 \\
\hline Marital status & $n=203$ & 100 \\
\hline Married & 108 & 53.2 \\
\hline Divorce & 60 & 29.6 \\
\hline Widowed & 35 & 17.2 \\
\hline
\end{tabular}

Source: Own survey result, 2017

Results in table 4indicate that, majority of the respondents (46.8\%) were in age group 31 to 40 years, followed by the respondents at age group 18 to 30 years $(27.1 \%), 18.7 \%$ and $7.4 \%$ were from age group between 41 to 50 \&above 50 years, respectively. Among the study population the above table (4) also shows, with no formal education consists $39.9 \%$ followed by read and write $(23.2 \%), 1-8^{\text {th }}$ grade accounts $13.8 \%, 9-12^{\text {th }}$ grade consists $10.8 \%, 6.4 \% \& 5.9 \%$ of the respondents were who have above diploma and Quran, respectively. The percentage of the respondents having secondary and higher education is $17.6 \%$. It is observed that majority of the respondents were married (53.2\%) followed by divorce and widowed (29.9\%and $17.2 \%)$, respectively. It is observed from the family's monthly income information that, near about $46.3 \%$ of the respondents have their monthly family income from 450 to 650 birr, $45.3 \%$ have from 651 to 800 birr and the remaining $8.4 \%$ of the respondents have more than 800 birr per month. Majority of the respondents' family size (69\%) consists between 6 to 8 families, $16.7 \%$ \& $14.3 \%$ of the respondent have between 9 to $12 \& 2$ to 5 families, respectively. Seventy-two $(71.9 \%)$ of the respondent were married before 18 years and only $28.1 \%$ of respondent married after 18 years. Most of the respondents were Muslim (94.1\%) and remaining 5.9\% were non-Muslim and also majority of the respondents (92.6\%)were Afar and $7.4 \%$ are non-Afar. 
Table 6. Age at marriage of the respondents

\begin{tabular}{lcc}
\hline Age at marriage & Frequency & Percent \\
\hline$<15$ Years & 77 & 37.9 \\
$16-20$ Years & 82 & 40.4 \\
$21-30$ Years & 44 & 21.7 \\
Total & 203 & 100.0
\end{tabular}

Source: Own survey result, 2017

Table 6 indicates that, a lion-share of the study respondents (40.4\%) were married between 16 to 20 years, $37.9 \%$ respondents married before 15 years of their age. Only $21.7 \%$ respondents were married at age between 21 to 30 years. This indicates majority of the respondents in the study area were married before the minimum age requirements. Similarly, (Alex Mugarura, 2016),age at marriage has long been regarded as one of the proximate determinants of fertility but the effect of age at marriage on fertility is not conclusive and this has remained of concern to developing countries.

Causes/reasons of early marriage

Early marriage is generally defined as marriage of a child under the age of 18 . The root causes or reasons of early marriage such as socio-cultural factors and economic reasons were presented and discussed here under.

Table7.Respondents' Perception on Socio-cultural Factors/Reasons of early marriage

\begin{tabular}{lcc}
\hline Social-cultural reasons & $\mathrm{n}=203$ & Percent $(100)$ \\
\hline inadequate education & 63 & 31.0 \\
social power & 42 & 20.7 \\
parent conflict & 17 & 8.4 \\
insuring virginity & 39 & 19.2 \\
Traditions & 26 & 12.8 \\
bad attitude & 13 & 6.4 \\
religious influences & 3 & 1.5 \\
\hline
\end{tabular}

Source: Own survey result, 2017

According to the survey (table 7), inadequate education (31\%), social power $(20.7 \%)$ and ensuring virginity $(19.2 \%)$ were the three major socio-culturalcauses for early marriage in the study area. Tradition (12.8\%), bad attitude (6.4\%) and religious influence (about $1.5 \%$ ) are also factors of early marriage recognized by respondents. In a similar vein, the FGD discussants and key informants in both kebeles identified various socio-cultural reasons for early marriage. Low levels of education, the presence of traditional norms, and lack of prevention of premarital sex, and security for the future were restated by the participants. A majority of the discussants emphasized that girls are expected to be virgins at their first marriage for their Absuma. Matured girls might experience premarital sex with or without their consent. This is very outrageous for themselves and the family at large. One of the elderly key informant stated that "virginity of girls at first marriage is a prize for the girls as well as for the families. Early marriage is the most effective way of attaining this social value". Similarly, according to Kerebih Asrese, Mulunesh Abebe (2014), conformity to social norms, seeking social status, ensuring virginity, access for resources, and security for the future and increasing fertility were the reasons of early marriage practice in South Wollo and East Gojjam zones of Amhara Region.

Table8.Economic reasons of early marriage identified by respondents

\begin{tabular}{lll}
\hline Economic reasons & $\mathrm{n}=203$ & Percent(100) \\
\hline inadequate economic resources & 40 & 19.7 \\
Unemployment & 40 & 19.7 \\
financial problems & 24 & 11.8 \\
inadequate family patterns & 66 & 32.5 \\
inadequate credit facilities & 18 & 8.9 \\
economic hardships & 15 & 7.4 \\
\hline
\end{tabular}

Source: Own survey result, 2017

The above table 8shows, inadequate family pattern (32.5\%), inadequate economic resources $(19.7 \%)$, and unemployment (19.7\%) were the three major economic reasons and also financial problems $(11.8 \%)$, inadequate credit facilities (8.9\%) and economic hardships (7.4\%) are economic reasons which contribute to the practice of early marriage in the study area. Similarly, FGD and key informant interview participants sated that poverty; drought and inadequate family pattern were the contributing factors of early marriage in the study area. Similarly, economic motives were the main causes of early marriage (Ruth Michael, 2014).

\section{Consequences of early marriage}

Respondents' perception on consequences of early marriage such as health related consequences (like early pregnancy, abortion, death and fistula) and socio-cultural consequence (like school attrition, termination of education, martial instability, domestic violence, excess work load, prostitution, migration and abduction) were presented and discussed as follow. 
Table 9. Perception of Respondents on Consequences of Early Marriage

\begin{tabular}{lcc}
\hline Health related consequences & Frequency $(\mathrm{n}=203)$ & Percent \\
\hline Death & 43 & 21.2 \\
Abortion & 59 & 29.1 \\
Fistula & 36 & 17.7 \\
unwanted pregnancy & 65 & 32.0 \\
\hline Socio-cultural consequences & $\mathrm{n}=203$ & 100 \\
\hline school Attrition & 27 & 13.3 \\
marital instability & 52 & 25.6 \\
termination of education & 57 & 28.1 \\
domestic violence & 36 & 17.7 \\
excess work load & 21 & 10.3 \\
Prostitution & 2 & 1.0 \\
Migration & 5 & 2.5 \\
Abduction & 3 & 1.5 \\
\hline
\end{tabular}

Source: Own survey result, 2017

Table 9 indicates that respondents who are aware of the harmful effects of early marriage identified a number of harmful effects of early marriage to a varying degree. The major health related consequences of early marriage were early pregnancy (32\%), abortion (29\%), death (21.2\%) and fistula (17.7\%). Also respondents identified socio- economic consequences of early marriage. Termination of education (28.1\%), martial instability $(25.6 \%)$ and domestic violence $(17.7 \%)$ were mentioned as the three top harmful effects of early marriage. School attrition $(13.3 \%)$, excess work load $(10.3 \%)$, migration $(2.5 \%)$, abduction $(1.5 \%)$ and prostitution $(1 \%)$ were also mentioned as the harmful effects of early marriage (Table 8). Similar opinions were given by FGD discussants and key informants. Divorce, prolonged labor, ill-health, fistula and school attrition were mentioned as harmful consequences of early marriage.

More importantly, health professional discussants underlined the health consequences of early marriage. Early marriage is associated with problems of prolonged and obstructed labor during delivery. Since the birth canal of the young girl will not allow the head of the fetus to pass easily, prolonged labor and death of the fetus in the uterus is observed, especially in remote rural areas where there is a lack of trained health professional to assist delivery. The discussants also pointed out that prolonged labor can damage the birth canal that leads to fistula and sometimes death of the mother due to bleeding. The reviewed studies on the consequences of early marriage have attempted to identify various impacts and consequences of early marriage (NCTPE, 2003; Guday, 2005; Path finder International Ethiopia, 2006). Similarly, according to Amsalu Hundie (2007), instability of marriage, problems related to sexual, reproductive health and child delivery, lack of educational opportunity and issues of poverty were the major consequences of early marriage among Selale Oromo Women. 
Table 12 Attitude of Respondents on Early Marriage

\begin{tabular}{|c|c|c|}
\hline Variables & Frequency & Percent \\
\hline 1.Early marriage negatively affects girl child education & 203 & 100 \\
\hline Strongly dis agree & 0 & 0 \\
\hline Disagree & 0 & 0 \\
\hline Not sure & 2 & 1 \\
\hline Agree & 44 & 21.7 \\
\hline Strongly agree & 157 & 77.3 \\
\hline \multicolumn{3}{|l|}{ One sample t-test $=24.251$} \\
\hline \multicolumn{3}{|l|}{ Mean(SD)4.76(0.499) } \\
\hline 2. Early marriage has health effect on girl child. & 203 & 100 \\
\hline Strongly disagree & 0 & 0 \\
\hline Disagree & 0 & 0 \\
\hline Not sure & 0 & 0 \\
\hline Agree & 35 & 17.2 \\
\hline Strongly agree & 168 & 82.8 \\
\hline \multicolumn{3}{|l|}{ One sample t-test $=31.138$} \\
\hline \multicolumn{3}{|l|}{$\operatorname{Mean}(\mathrm{SD})=4.83(0.379)$} \\
\hline 3. Early marriage has Physiological Implication on Girl Child. & 203 & 100 \\
\hline Strongly dis agree & 0 & 0 \\
\hline Disagree & 0 & 0 \\
\hline Not sure & 11 & 5.4 \\
\hline Agree & 64 & 31.5 \\
\hline Strongly agree & 128 & 63.1 \\
\hline \multicolumn{3}{|l|}{ One sample t-test $=13.796$} \\
\hline \multicolumn{3}{|l|}{$\operatorname{Mean}(\mathrm{SD})=4.58(0.595)$} \\
\hline 4. The custom, tradition and Religion are contributing to early marriage. & 203 & 100 \\
\hline strongly disagree & 0 & 0 \\
\hline Disagree & 0 & 0 \\
\hline not sure & 4 & 2.4 \\
\hline Agree & 41 & 19.7 \\
\hline Strongly agree & 158 & 77.8 \\
\hline \multicolumn{3}{|l|}{ One sample t-test $=22.857$} \\
\hline \multicolumn{3}{|l|}{$\operatorname{Mean}(\mathrm{SD})=4.76(.473)$} \\
\hline 5. Economic situation is contributing to girl child marriage. & 203 & 100 \\
\hline strongly disagree & 2 & 1.0 \\
\hline Disagree & 5 & .5 \\
\hline not sure & 15 & 7.4 \\
\hline Agree & 130 & 64 \\
\hline Strongly agree & 55 & 27.1 \\
\hline \multicolumn{3}{|l|}{ One sample t-test $=3.423$} \\
\hline \multicolumn{3}{|l|}{$\operatorname{Mean}(\mathrm{SD})=4.16(0.656)$} \\
\hline 6. Girl child marriage is open to domestic violence and sexual abuse. & 203 & 100 \\
\hline strongly disagree & 0 & 0 \\
\hline Disagree & 0 & 0 \\
\hline not sure & 3 & 1.5 \\
\hline Agree & 55 & 27.1 \\
\hline Strongly agree & 145 & 71.4 \\
\hline \multicolumn{3}{|l|}{ One sample t-test $=20.304$} \\
\hline \multicolumn{3}{|l|}{$\operatorname{Mean}(\mathrm{SD})=4.70(0.491)$} \\
\hline $\operatorname{Mean}(\mathrm{SD})=4.85(0.383$ & & \\
\hline
\end{tabular}

Source: Own survey result, 2017

In the table above (12), $73.3 \%$ of the respondents strongly agreed early marriage can affect girl child education, $21.7 \%$ of the respondents agreed with the same view, none of the responds strongly disagreed with the view only $1 \%$ of the respondents were not sure of the view. The mean value of the respondents' responses on effects of early marriage on child education is 4.76. This implied that early marriage affects girl child education. The table above (12) also shows that $88.2 \%$ of the respondents strongly agreed that early marriage has health effect on girl child $17.8 \%$ the respondents agreed with the same view, in contrast none of the respondents strongly disagreed that early marriage has health effect on girl child. The mean value of respondents 'response on health effects of early 
marriage is 4.83 . From the foundlings the frequency of the highest respondents agreed with the above statement, measured the highest frequency.

Above table (12) showed that $63.1 \%$ of the respondents strongly agreed that early marriage has physiological implication on girl Child, $31.5 \%$ of the respondents agreed with the above statement, in contrast, $5.4 \%$ of the respondents not sure with the same view. The table (12) shows that $77.8 \%$ of the respondents strongly agreed that the custom, tradition and Religion are contributing factor to early marriage practice, $19.7 \%$ of the same respondents also agreed with the same views, in contrast, $2.4 \%$ of the respondents not sure for the statement. The mean value of respondent on the contribution of customs, traditions and religion for early marriage is 4.76 . Therefore, the highest respondents were perceived that customs, traditions religious can have contributed for practice of early marriage.

Table 12 shows that $27.1 \%$ of the sample respondents strongly agreed Economic situation is contributing to girl child marriage, $64 \%$ of the same respondents agreed with the above statement, and $7.4 \%$ of the respondents not sure, $1 \%$ of the respondent strongly disagreed while $0.5 \%$ of the respondents disagree. The mean value of respondents on economic situation can contribute to early marriage is 4.16 . Table12 also indicates that the mean value of the respondents' response that early marriage is exposed to domestic violence and sexual abuse or not of early married women is 4.70 . The above table (12) also shows that $2 \%$ of the respondents strongly agreed that Men \&women can make decision on marriage, use of contraception and first pregnancy in equal manner, $2 \%$ of the respondents agreed, in other word, $42.9 . \%$ of the respondents strongly disagreed with the above statement while $31 \%$ and $22.2 \%$ of the respondents not sure and disagreed respectively. Table 13. Parameter estimates of binary logistic regression model

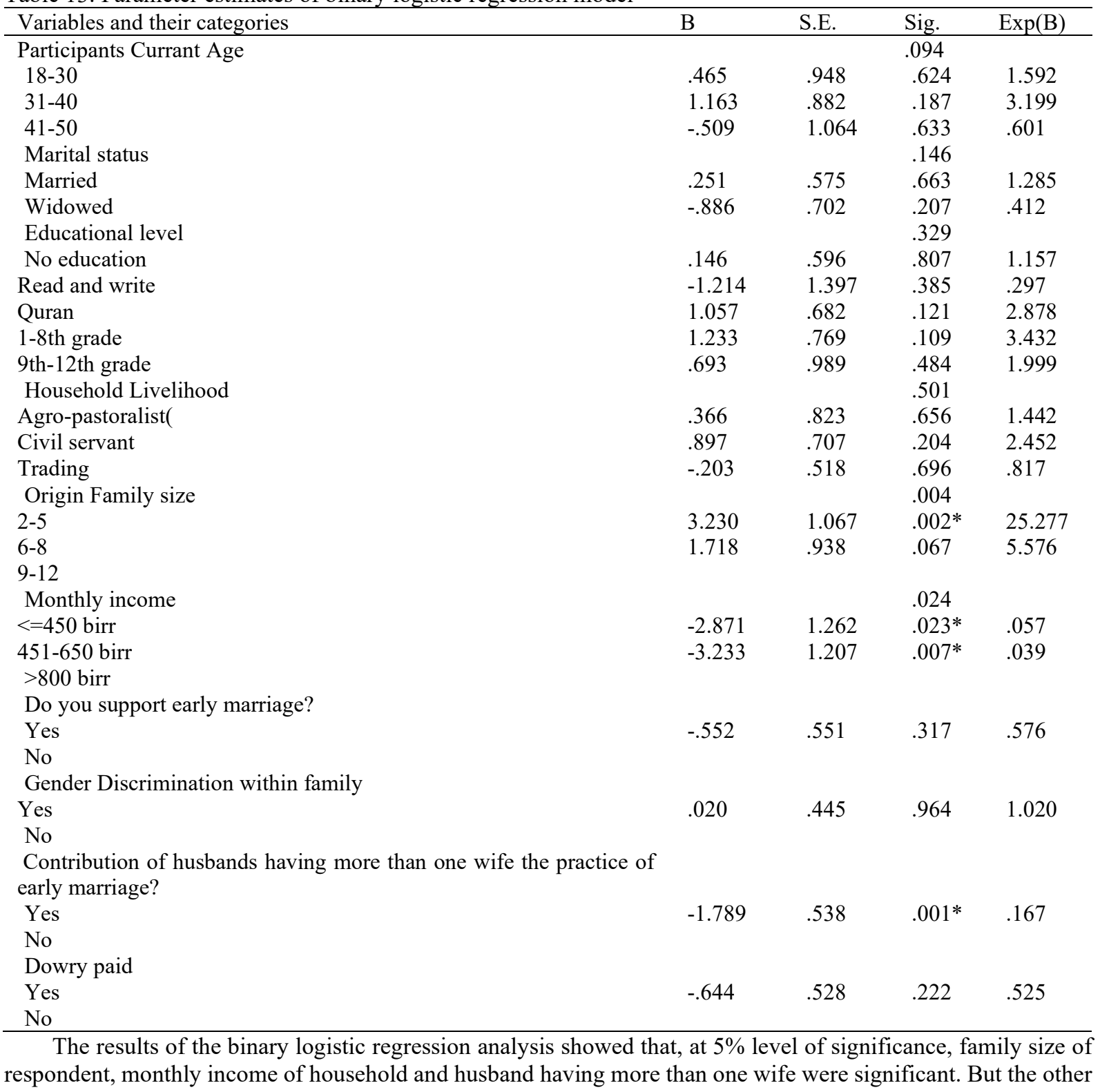


parameters were insignificant.

In line with this study, similar study in Bangladish (sarker obidea nasirn and K.M Mustafizur Rahma, 2012) education, monthly income of the respondent and religion were the key determing factors for the practice early marriage.

\section{CONCLUSIONS AND RECOMENDATIONS}

This paper has shown that child marriage is a socio-cultural practice in the study area. It is still widely sanctioned, even though it is a violation of the human rights of young girls due to various motives. For study, two Kebeles were selected using purposive sampling and from the two Kebeles, a total of 203 sample married women were selected using random sampling technique. Also, 10 key informants and two focus groups were selected to gather data. Household survey, key informant interviews and focus group discussion were used to gather data. Therefore, this study revealed that early marriage is prevalent in the study areas. According to respondents' perception, Sociocultural and economic motives were the major reasons for the persistence of this discriminatory practice in the study area. This study also explores that because of the socio-cultural and economic reasons of early marriage, early married girls were exposed for psychological traumas, various violence, denial of social services, and health related problems and other socio-cultural problems. The study further indicated that majority of girls were married below the age of 18 years and also families \&relatives were the decision makers for girls' first time marriage. The study also brought to light that majority of the respondents were arguing that early marriage has negative effects on early married girls' health, education, psychological impact, expose to domestic violence and sexual abuses. Results from binary logistic regression model shows that out of the entire selected variables of respondents', family size, income level of households and husbands having more than one wife were significant at 5\% probability level. Based on the result of this study, the following recommendations are given:

$>$ The level of education for women in the study area is low. So this study recommends that raising the level of education of women could contribute to decrease in the rate of early marriage practice in the study area.

$>$ Providing economic opportunities to girl child. Poverty is one of the major factors underpinning early marriage. Efforts to improve the access of young married and non-married girls to economic resources should focus on expanding employment and entrepreneurial opportunities.

$>$ To the extent possible, awareness creation of the effect of early marriage should be promoted by family counselors, religious leaders, policy makers' social workers and other helping professionals at regional level.

$>$ Further study with additional predictor variables have to be made so as to address the issues raised in this study.

\section{REFERENCE}

$>$ Amsalu Hundie (2007), Causes and Consequences of Early Marriage among Selale Oromo Women: The Case Study of Hidabu Abote and Kuyu Woredas, North Shewa Zone, Oromia National Regional State

$>$ CSA (Central Statistical Authority) (2012). Summary and statistical report of Population and Housing Census. Addis Ababa, Ethiopia

$>$ Guday Emirie, (2005) Early Marriage and its Effects on Girl's Education in Rural Ethiopia: The Case of Mecha Woreda in West Gojjam, North-Western Ethiopia. A Doctoral Dissertation in Ethnology, Gottingen University, Germany

$>$ Ingrid, L. (2009). Early marriage and education, Newsletter No_ 7 - Early marriage and Education EENET.mh

$>$ Kerebih Asrese, Mulunesh Abebe. Early Marriage in South Wollo and East Gojjam Zones of the Amhara Region, Ethiopia. Humanities and Social Sciences. Vol. 2,No. 2,2014, pp. 11-16. doi:10.11648/j.hss.20140202.11

$>$ Ruth Michael, (2014) Factors contribute to early marriage among teenagers in rural areas In Kasulu District Council in Partial Fulfillment of the requirements for award of Degree of Masters of Science in Human Resource Management of Open University of Tanzania.

$>$ Mahdere Paulos (2006). Early Marriage in Ethiopia. Ethiopian Women Lawyers Association, Addis Ababa, Ethiopia

$>$ National Committee on Harmful Traditional Practices (2003) Old Beyond Imaginings: Ethiopia, Harmful Traditional Practices Addis Ababa United Printers

$>$ Pathfinder (2006). Pathfinder's did a mixed-methods study on the causes and Consequences of child Marriage in Amhara.

$>$ Pathfinder International/Ethiopia (2009) revealed that its impacts on intimacy and Husband-wife Relation Population Council. (2008). Child ma

$>$ sarker obidea nasirn and K.M Mustafizur Rahma (2012), Factors affecting early marriage and early conception of women: A case of slum areas in Rajshahi City, Bangladesh 